\title{
Continuous renal replacement therapy increased plasma cholinesterase activity in a case of acute organophosphate poisoning
}

\author{
In Ho Kwon, Jinwoo Jeong, Yuri Choi \\ Department of Emergency Medicine, Dong-A University College of Medicine, Busan, Korea
}

Extracorporeal removal of organophosphate from blood has been proposed, but the efficacy of hemodialysis and hemoperfusion has not been established. We report a case of organophosphate poisoning in which continuous renal replacement therapy (CRRT) was applied with conventional indications and was found to increase plasma cholinesterase levels by hemodiafiltration. A 73-year-old male was found unconscious at home and was brought to the emergency department by ambulance. An empty bottle of Supracide insecticide, of which the active ingredient is methidathion, was found beside him. CRRT was initiated because he showed signs of oliguria and acidosis with an unstable hemodynamic condition. Although his condition improved temporarily after CRRT initiation, it subsequently deteriorated, and he died despite maximal supportive effort. His prefilter plasma cholinesterase levels remained at $<200 \mathrm{U} / \mathrm{L}$ for 3 days, while his postfilter levels were 358 $\mathrm{U} / \mathrm{L} 1$ hour after CRRT initiation and they were $689 \mathrm{U} / \mathrm{L} 18$ hours later. Our case suggests that CRRT might play a role in treating organophosphate poisoning by possibly eliminating organophosphate.

Key Words: cholinesterase; continuous renal replacement therapy; decontamination; organophosphate poisoning

Mortality from organophosphate poisoning is high, despite recent advancements in critical care strategies [1,2]. Extracorporeal removal of organophosphate from blood has been suggested, but the efficacy of hemodialysis and hemoperfusion is not well established [3,4]. The major concern is a large distribution and volume of organophosphate compounds due to their high lipid solubility [5]. If its ability to remove organophosphate is confirmed, continuous renal replacement therapy (CRRT) may have a theoretical advantage over hemodialysis or hemoperfusion sessions because CRRT continuously eliminates substances. We report a case of organophosphate poisoning in which CRRT was applied with conventional indications and was found to increase plasma cholinesterase levels by hemodiafiltration.

\section{CASE REPORT}

The patient never had a chance to provide consent because of his critical condition. Approval from the Institutional Review Board of Dong-A University Hospital have been ob-

\section{Case Report}

Received: June 6, 2021

Revised: July 1, 2021

Accepted: July 6, 2021

\section{Corresponding author}

Jinwoo Jeong

Department of Emergency Medicine,

Dong-A University College of

Medicine, 32 Daesingongwon-ro,

Seo-gu, Busan 49201, Korea

Tel: +82-51-240-2778

Fax: +82-51-240-5309

E-mail: advanced@lifesupport.pe.kr

Copyright (C) 2021 The Korean Society of Critical Care Medicine

This is an Open Access article distributed under the terms of Creative Attributions Non-Commercial License (https:// creativecommons.org/li-censes/by-nc/4.0/) which permits unrestricted noncommercial use, distribution, and reproduction in any medium, provided the original work is properly cited. 
tained for publication without an informed consent (No. DAUHIRB-21-054).

A 73-year-old male was found unconscious at home and was brought to the emergency department by ambulance. An empty bottle of Supracide insecticide, of which the active ingredient is methidathion, and a suicide note were found beside him. His past medical history was unremarkable and he had no history of hypertension or diabetes according to his family. His body weight was approximately $45 \mathrm{~kg}$. At presentation, the patient was comatose, with a Glasgow coma scale score of 3 .

Both his pupils were pinpoints. His vital signs were as follows: blood pressure, $120 / 100 \mathrm{~mm} \mathrm{Hg}$; pulse rate, 108 per minute; respiration rate, 24 per minute; and body temperature, $36^{\circ} \mathrm{C}$. Salivation and rales increased in both lung fields. The patient was intubated and placed on mechanical ventilation. Activated charcoal was given via a nasogastric tube. Repeated boluses of atropine were given in 2-mg aliquots until clear lung sounds could be heard, and then continuous infusion was started at $1 \mathrm{mg} / \mathrm{hr}$ and titrated until clear breathing sounds were heard. An infusion of pralidoxime was started at a rate of $500 \mathrm{mg} / \mathrm{hr}$. The initial laboratory results were as follows: arterial pH, 7.220; partial pressure of carbon dioxide $\left(\mathrm{PCO}_{2}\right)$, $36.7 \mathrm{~mm} \mathrm{Hg}$; $\mathrm{PO}_{2}, 59.9 \mathrm{~mm} \mathrm{Hg}$; and bicarbonate, $14.7 \mathrm{mmol} / \mathrm{L}$. Serum lactate was $7.8 \mathrm{mmol} / \mathrm{L}$, blood urea nitrogen was 18 $\mathrm{mg} / \mathrm{dl}$, and serum creatinine was $1.2 \mathrm{mg} / \mathrm{dl}$. The initial plasma cholinesterase level was $<200$ units/L, which is the laboratory's lowest detectable level.

Approximately 6 hours after presentation, the patient's blood pressure dropped to $70 / 40 \mathrm{~mm} \mathrm{Hg}$, and norepinephrine infusion was started and titrated to blood pressure. The norepinephrine dose required to maintain his systolic blood pressure above $90 \mathrm{~mm} \mathrm{Hg}$ was $0.44 \mu \mathrm{g} / \mathrm{ml} / \mathrm{min}$. The urine output decreased to $25 \mathrm{ml} / \mathrm{hr}$. Blood gas analysis revealed $\mathrm{pH}$ 7.154, $\mathrm{PCO}_{2} 20.8 \mathrm{~mm} \mathrm{Hg}, \mathrm{PO}_{2} 323 \mathrm{~mm} \mathrm{Hg}$, and bicarbonate 7.1 $\mathrm{mmol} / \mathrm{L}$. Although the serum creatinine was $1.46 \mathrm{mg} / \mathrm{dl}, \mathrm{CRRT}$ was initiated because the patient had oliguria, acidosis, and an unstable hemodynamic condition. The prescription for renal replacement therapy is continuous venovenous hemodiafiltration (CVVHDF) via a jugular venous catheter, blood flow of $120 \mathrm{ml} / \mathrm{min}$, dialysate flow of $500 \mathrm{ml} / \mathrm{hr}$, substitute flow of 1,000 $\mathrm{ml} / \mathrm{hr}$, and fluid removal of $200 \mathrm{ml} / \mathrm{hr}$.

Therefore, the total effluent flow rate was $37.7 \mathrm{ml} / \mathrm{kg} / \mathrm{hr}$. The norepinephrine requirement decreased and remained between $0.09-0.13 \mu \mathrm{g} / \mathrm{kg} / \mathrm{min}$ for 20 hours after CRRT initiation. However, the patient's condition progressively deteriorated and despite maximal ventilatory, hemodynamic, and renal support and antidote therapy he died on the fourth day. On the second and third days, his plasma cholinesterase levels were measured with prefilter and postfilter blood drawn at the same time. The prefilter plasma cholinesterase levels remained at $<200 \mathrm{U} / \mathrm{L}$, while postfilter levels were reported as $358 \mathrm{U} / \mathrm{L} 1$ hour after CRRT initiation and $689 \mathrm{U} / \mathrm{L} 18$ hours after.

\section{DISCUSSION}

We presented a case in which CRRT was found to increase postfilter plasma cholinesterase levels. Although plasma cholinesterase levels, i.e., butyrylcholinesterase, do not correlate with symptom severity; it is known to inversely correlate with plasma organophosphate levels and is used as a surrogate marker of organophosphate concentrations because organophosphate concentrations are not widely available in clinical settings [3]. Additionally, plasma cholinesterase is thought to have a therapeutic effect by binding to organophosphate compounds $[5,6]$.

Although extracorporeal removal is not a standard treatment for organophosphate poisoning, there are some reports of its application. Güven et al. [6] applied plasmapheresis on the fifth day after organophosphate poisoning to a patient with sepsis and noted that plasma cholinesterase levels increased from 2,101 U/L to 6,144 U/L and remained high. Bo [7] reported that 3-4 sessions of repeated hemoperfusion within 48 hours after poisoning resulted in faster normalization of cholinesterase levels and improved survival. However, hemoperfusion is not as widely available for CRRT for emergency management of poisoned patients, especially in high-income countries where the incidence of pesticide poisoning is decreasing [8].

In our case, CRRT was initiated because oliguric acute kidney injury was indicated, and the patient's condition was at least temporarily stabilized, although the multiorgan damage from the organophosphate eventually caused his death. Although previous reports indicated that plasma cholinesterase levels were elevated after initiation of extracorporeal therapies, plasmapheresis and hemoperfusion are not as readily available as CVVHDF, which was used in this case. Also, it is possible that the increase in cholinesterase level in a previous report was due to other conventional therapies, such as oximes. Our case showed that CVVHDF could possibly eliminate organophosphate in the filter, resulting in increased postfilter plasma cholinesterase. This suggests that CRRT might have a 
role in treating organophosphate poisoning.

\section{CONFLICT OF INTEREST}

No potential conflict of interest relevant to this article was reported.

\section{FUNDING}

None.

\section{ACKNOWLEDGMENTS}

None.

\section{ORCID}

In Ho Kwon

https://orcid.org/0000-0002-2518-6951

Jinwoo Jeong

https://orcid.org/0000-0003-1745-5127

Yuri Choi

https://orcid.org/0000-0003-1214-0820

\section{AUTHOR CONTRIBUTIONS}

Conceptualization: JJ. Writing-original draft: IHK. Writingreview \& editing: JJ, YC.

\section{REFERENCES}

1. Moon J, Chun B. Utility of red blood cell acetylcholinesterase measurement in mechanically ventilated subjects after organophosphate poisoning. Respir Care 2014;59:1360-8.

2. Moshiri M, Darchini-Maragheh E, Balali-Mood M. Advances in toxicology and medical treatment of chemical warfare nerve agents. Daru 2012;20:81

3. Eddleston M, Buckley NA, Eyer P, Dawson AH. Management of acute organophosphorus pesticide poisoning. Lancet 2008;371:597-607.

4. Peng A, Meng FQ, Sun LF, Ji ZS, Li YH. Therapeutic efficacy of charcoal hemoperfusion in patients with acute severe dichlorvos poisoning. Acta Pharmacol Sin 2004;25:15-21.

5. Peter JV, Moran JL, Pichamuthu K, Chacko B. Adjuncts and alternatives to oxime therapy in organophosphate poisoning: is there evidence of benefit in human poisoning? A review. Anaesth Intensive Care 2008;36:339-50.

6. Güven M, Sungur M, Eser B. The effect of plasmapheresis on plasma cholinesterase levels in a patient with organophosphate poisoning. Hum Exp Toxicol 2004;23:365-8.

7. Bo L. Therapeutic efficacies of different hemoperfusion frequencies in patients with organophosphate poisoning. Eur Rev Med Pharmacol Sci 2014;18:3521-3.

8. Bouchard J, Lavergne V, Roberts DM, Cormier M, Morissette G, Ghannoum M. Availability and cost of extracorporeal treatments for poisonings and other emergency indications: a worldwide survey. Nephrol Dial Transplant 2017;32:699-706. 